\title{
So Close and Yet So Far: The Distant Heritage of the Historical Urban Landscapes of Residential Districts of Tartu, Estonia
}

\author{
Kadri Kallast $^{1}{ }^{10}$
}

Published online: 5 June 2020

(c) The Author(s) 2020

\begin{abstract}
The urban landscapes of residential areas outside of historic city centres have been increasingly recognized as cultural heritage and as potentially powerful source of meaning for local identities. In Estonia, many municipalities have established milieu protection areas, among them the town of Tartu which has currently ten areas, mainly comprising residential areas developed in the late nineteenth and early twentieth century. The authorised heritage discourse proceeds from the historical values in these areas, yet in its dialogue with the public, be it via the comprehensive plan or in discussions about single projects, it focuses on setting restrictive conditions to construction and renovation, instead of properly communicating the historical values. The neighborhood societies' input to the comprehensive plan indicates a lack of sufficient links between the historical urban landscapes and the inhabitants' lives, often leading to the local heritage to be distant for them which in turn tends to lead to maltreatment of the historical substance. Promoting community identity formation with a narrative approach would favor these links to develop, favoring the inhabitants of these historical urban landscapes to continue the life and stories of the heritage.
\end{abstract}

Keywords Historical urban landscape · Urban planning · Comprehensive plan · Heritage values $\cdot$ Community identity

\section{Introduction}

In the framework of urban semiotics, three main approaches to urban environments have evolved over time: (1) the city as a sociocultural phenomenon, (2) focus on the perception of the urban environment, and (3) studying the urban space as a sign

Kadri Kallast

kadri.kallast@artun.ee

1 Cultural Heritage and Conservation at the Estonian Academy of Arts, Tartu, Estonia 
system [17, p. 449]. Each of these three perspectives is relevant to a semiotic study of urban heritage, as they (1) view cities as semiotic mechanisms that express culture and its changes over time, (2) consider individual and collective images of the city via the concept of cognitive mapping, and (3) focus on communicative situations in the urban space, including the discourses of urban planning, production of social relations, and the communicative attributes of architecture [17, pp. 449-451]. Additionally, urban environments have become increasingly approached through the concept of landscape, especially in the context of urban heritage.

The heritage discourse has been broadening regarding what kind of urban environments are treated as historical landscapes and what defines their value. Already Gustavo Giovannoni, the first to designate the notion 'urban heritage' [7, p. 132], stated that the valued features of cities and villages derive from the combination of their landscape, building ensembles and the architecture of the less prominent buildings [12, p. 176]. Residential buildings that constitute the neighbourhoods are often not considered to hold high architectural or historical value individually but their group value is noted to be essential for the local atmosphere, and their role in forming local identities is estimated to be much more substantial than of historical monuments [9, p. 290].

In Estonia, since the 1960s, the focus in built heritage shifted from single buildings to complete architectural ensembles, e.g. cores of provincial towns, farm or manor house complexes and villages [33, p. 212]. Today there are twelve heritage conservation areas in the country, among which eleven are historic town centres and one is an agricultural landscape. The protection of national heritage, including heritage conservation areas and single monuments, is established on the state level. In addition, since the Planning Act of 2002 it has become mandatory for municipalities to determine the environmentally valuable areas in every plan, especially in comprehensive plans, and set the conditions for construction there [13, p. 105]. Ever since, many of the Estonian municipalities have established 'milieu protection areas', i.e. historic urban or rural areas that are considered to hold cultural and environmental values. The conditions for land use, construction and renovation in these areas varies widely and is dependent on the local comprehensive plans. Some only focus on the preservation of historical plot structure and the volume and style of the buildings, while others can be very precise about architectural details and how they should be restored.

The recent decades have witnessed several Estonian town districts that consist of mostly nineteenth and early twentieth century wooden residential buildings transform from written-off 'decay districts' into highly valued living spaces. The historical architectural substance, original plot structure, traditional greenery, street networks and other landscape elements in these areas have been under pressure from real estate developers to tear down the depreciated buildings and convert these areas into more densely populated areas with modern housing. While many of these districts have become protected from these harsh developments by local plans that prevent them, continuous destruction and alteration on a smaller scale can be detected in all of these areas. 


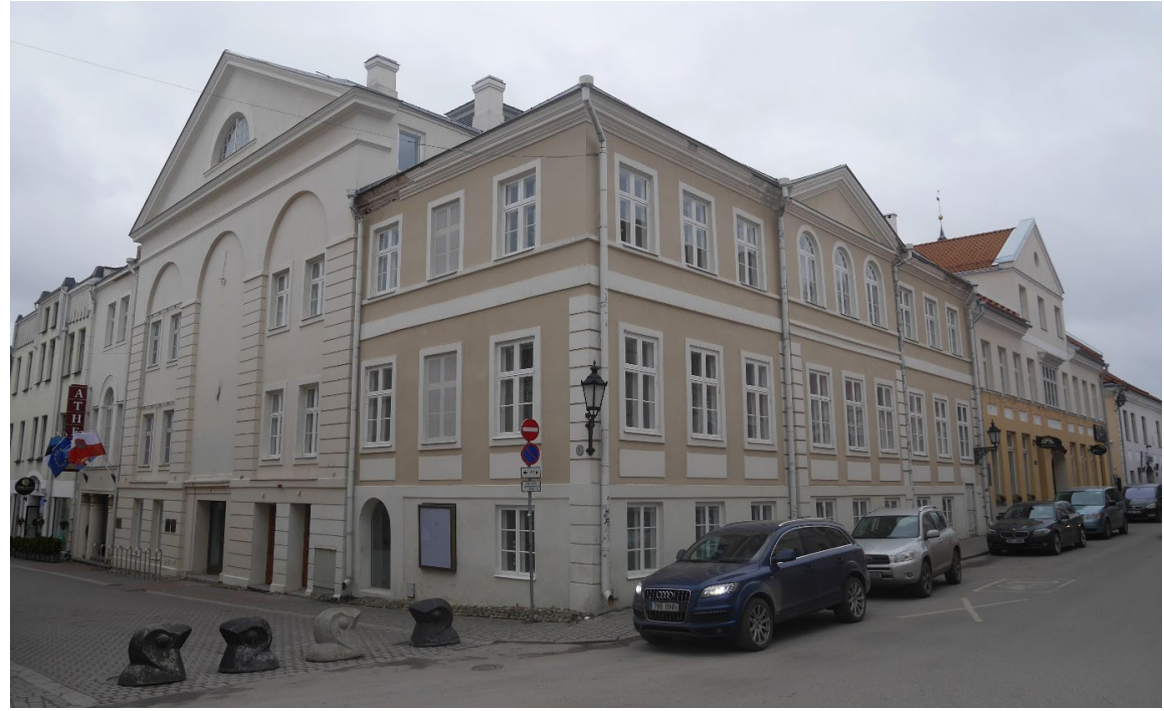

A street corner in the old town of Tartu with characteristic neo-classical style buildings

The heritage conservation area in the old town center of Tartu was created in 1966. The historical town center is made up of mainly late 18th and early nineteenth century street networks and neo-classical style buildings built around and onto medieval remains and memories. The first four urban protective areas outside of the old town were established in the mid-1990s, nine more were added with the previous comprehensive plan in 2005, since then named as milieu protection areas. The latest comprehensive plan of Tartu was established in September 2017, as a result of merging two areas into one and excluding a few smaller areas the number of milieu

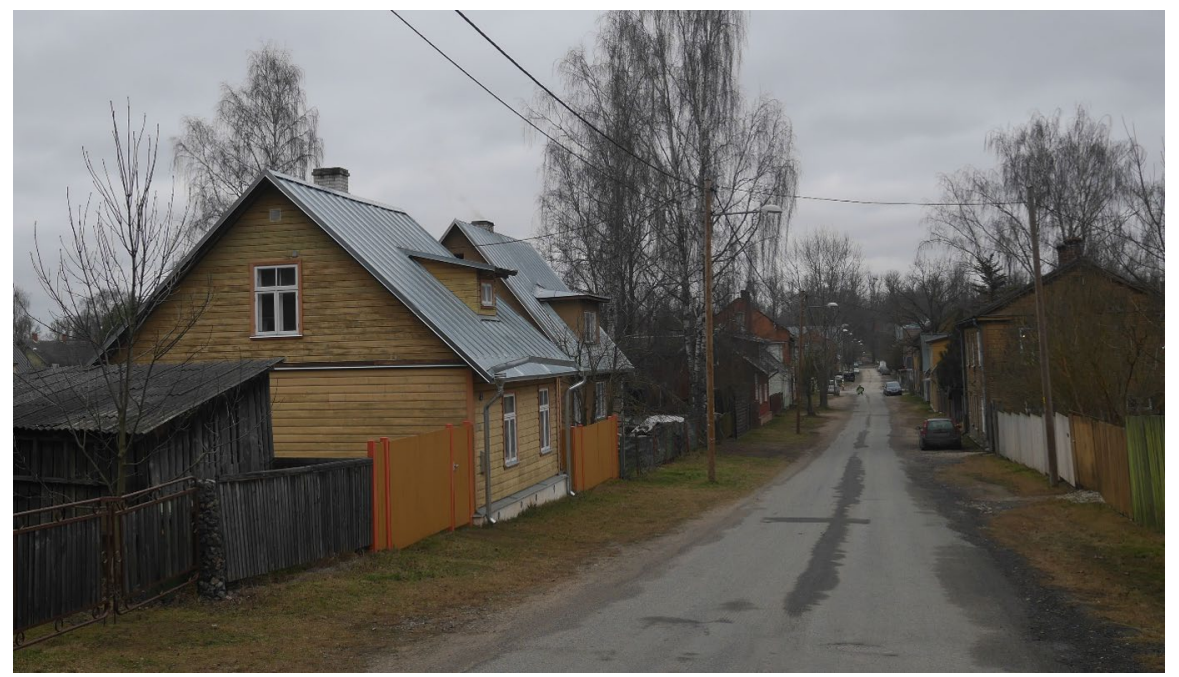

Milieu protection area of Supilinn in Tartu 
protection areas in Tartu is currently ten. The milieu protection areas are generally residential districts evolved in late nineteenth and early twentieth century.

\section{Approaching the Distance of the Local Urban Heritage}

In this paper I apply the framework of critical discourse analysis (CDA), which is advocated to make a 'semiotically sophisticated' contribution for cultural heritage studies [37, p. 340] and is applicable not only to verbal expressions but to any type of semiotic material [11]. Following the schematic framework of CDA [11, pp. 236-240], I will:

1. bring forward a social problem with a semiotic aspect, focusing on the production of knowledge: in this case study, the highlighted problem is the distance of local urban heritage and how the authorised heritage discourse, ${ }^{1}$ particularly via urban planning, maintains the gap between the urban heritage and its habitants;

2. identify obstacles to the social problem being tackled, in order to understand how the problem is rooted in the social organization: the paper points out which circumstances have led to the formation of the authorised heritage discourse and the establishment of the milieu protection areas, e.g. the maltreatment of historical buildings and discontinuity of building traditions, and also which sociopolitical factors contribute to the dissonance of the local urban heritage;

3. consider whether the social order needs this problem to exist, how it may benefit from it not being resolved: the following analysis leads to the conclusion that dominating the authorised heritage discourse gives the municipality a desired advantage in, both, the process of collaborative planning and dealing with conflicts that can occur with construction and renovation projects;

4. look for solutions to overcome the problem by proposing ways to change how social life is organized: I suggest promoting community identity in conjunction with more cohesive narratives about the historical urban landscapes.

As a precaution, Fairclough adds a fifth and final stage to the framework of CDA that invites the analysts to reflect on their own social positioning that affects the outcome of all previous stages. In this case, reminding me to keep in mind that my own relation to the milieu protection areas has grown out of my work experience as an advocator for its values and preservation as presented in the administrative documents.

As I can tell from my own experience from working as a heritage specialist in Tartu city council in years 2014-2016, the preservation of the urban heritage

\footnotetext{
1 The term 'authorised heritage discourse' is well explained in Laurajane Smith's 'Uses of Heritage': 'The AHD [authorised heritage discourse] focuses attention on aesthetically pleasing material objects, sites, places and/or landscapes that current generations 'must' care for, protect and revere so that they may be passed to nebulous future generations for the 'education', and to forge a sense of common identity based on the past. [...] One of the consequences of the AHD is that it defines who the legitimate spokespersons for the past are.' [28, p. 29].
} 
in milieu protection areas is often problematic because these areas are not easily acknowledged as cultural heritage by the residents. The differences between national heritage (the old town and singular monuments around the town) and the milieu protection areas has definitely challenged the concept of built heritage. The assets of age, architectural uniqueness, connections to historical events and persons, which are traditionally considered to be features of built heritage, are a lot less present in the milieu protection areas. Whilst national heritage conservation areas include mainly medieval or modern era districts, the milieu protection areas are in large suburbs and boroughs that were built during the end of the nineteenth century and the beginning of the twentieth century [1, p. 20]. The approach to the wood-built dwelling areas at the time when they were constructed was that 'they are cheap and temporary and must make way for stone buildings as soon as the financial position of the population has improved' [35, p. 178], and this attitude has somewhat lingered on in the public's eye. Furthermore, the national heritage listing consists largely of public buildings, manor houses, churches which present the great architectural styles like baroque, neo-classicism or gothic, often with unique architecture and details, but in the milieu protection areas one will find mainly wooden apartment buildings, many of them built following very similar blueprints, also with repeating decorative elements.

The maltreatment of the historical buildings has a lot to do with the alienation from building traditions. As elsewhere in the Western world, local traditions, including those of construction and restoration of homes, 'are exposed to the

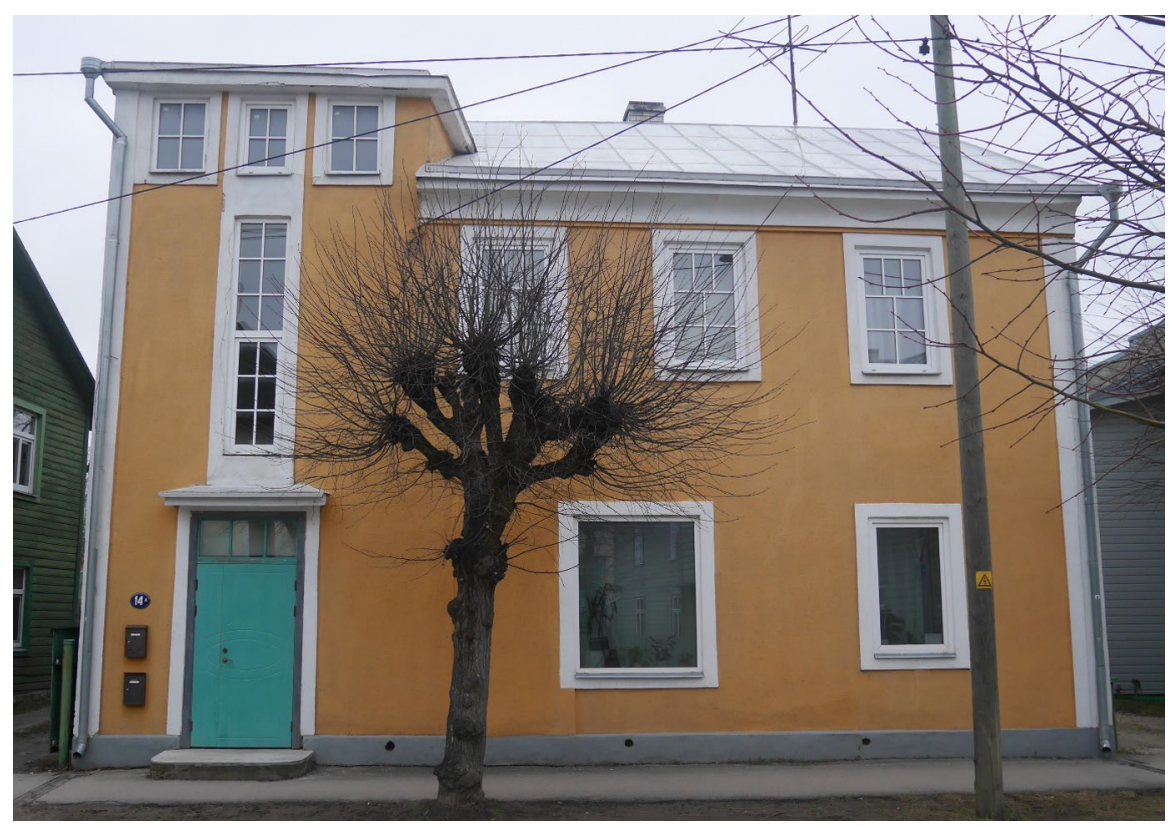

An historical building's facade in Karlova area has been altered with plastic windows and a modern front door 
onslaught of a sweeping globalization' [4, p. 31], driven by modern technology and materials. One of the reasons for stating the need to establish the protection of environmentally valuable areas in the first place was that property owners and constructors did not have sufficient knowledge about local building traditions and architectural values [13, p. 105]. There is still little knowledge about the benefits of using traditional materials and recognition of historical architectural details among home-owners in the milieu areas.

But the differences from national heritage and forgotten building traditions are far from being the only causes for the residential districts' historical urban landscapes' heritage to be distant and dissonant for the locals. The first thing we need to consider when discussing the dissonance of the urban heritage in Estonia in general, is the country's sociopolitical history. The historical built environment is influenced mainly by German, Polish, Swedish and Russian culture, along with influences of manor architecture from other Western European countries [24] and also more often than not originally owned by foreigners. This can cause the urban architecture to also be perceived as other instead of our. Another interruption caused in the middle of the last century was the plan to demolish many of the pre-modernist districts and rebuild them according to Stalinist plans. The regime did not find these urban environments to hold any remarkable value in their eyes, more on the contrary, it may have been its wish to remove the reminders of preSoviet times, the general positivist ideas of modernism were also embodied in the plans, and the historical urban landscape, well, it was just made to look outdated. This view on the historical urban landscapes has also stuck on many of today's inhabitants.

Yet another aspect contributing to the distance of milieu area heritage, is the lack of personal histories related to the area. Several economic and social factors cause the resettlement of individuals and families to other towns and town districts. As a university town Tartu has been and continues to be a destination for new inhabitants every year, many of them come here without any personal histories related to the area nor much knowledge of its history. But also for families who have stayed tied to the same district over decades, the Soviet occupation in Estonia ${ }^{2}$ caused a violent change in their relation to the environment. During the occupation period, the living situation was controlled by the regime, which needed to house their troops and administration in Estonia and the way to make space for them was to force the locals out of their homes and into tight living spaces where several families would have to live together in one apartment. So what the living memory recalls about the ways of life in these dwelling areas is rather contested, to say the least. It has been observed in many Post-Soviet states that the totalitarian period has caused an interruption in a society's normal continuity which has weakened social trust, brought about the lack of community sense, and caused local heritage to become so contested and dissonant that instead of uniting the community it deepens the feeling of exclusion [9, p. 288; 23].

\footnotetext{
${ }^{2}$ Estonia was occupied by the Soviet Union in 1940-1941 and 1944-1991.
} 
We can speculate that, perhaps, in countries like Estonia, that have undergone totalitarian regimes which forced on unwanted changes in the physical environment and living conditions (to say extremely mildly), once liberated from the regime, the will to forcefully reorganize the environment is particularly strong in the society. So much so that people feel reluctant to follow the rules of the new administration, even that of an independent democratic nation state, when it comes to making decisions about their own property, as this right feels like something the nation had awaited and fought for during a long period of time. The sense of being a rightful property owner and in full control of what happens to this property is important in the postSoviet societies, and the administration's engagement with one's right to treat their property, as in the case of establishing rather strict rules in the milieu protection areas, could be interpreted as an unrightful intrusion.

Due to all of these problematic aspects in the communities' relation to the local living environment, they often don't claim their local historical urban landscapes to be their heritage. Then why persist on preservation of these areas as heritage? Built space is 'the physical result of a social productive process' [16], and historic cities are regarded in the cultural heritage discourse to be the most complete and most tangible incarnations of culture [4, p. 28]. The urban landscapes of the milieu protection areas are regarded to contain meaningful substance that can continue to provide insight to the local histories and facilitate to keep a bond between the past and the present. As Stuart Hall has famously pointed out, cultural heritage is a powerful source of meaning that acts as a mirror of the society, excluding those who cannot see themselves in its reflection [14].

So, we can reconceptualize the communities' position regarding the local heritage as a problem of not recognizing themselves in the reflection of culture that the heritage is representing. In order to preserve historic environments, it is important for the local people to recognise it as meaningful, valuable, relatable, and at the best case as their heritage, since 'an environmentally valuable area has an identity value only in the case that people realise its value and wish to preserve it' [13, p. 107]. To achieve that, Francesco Bandarin and Ron van Oers emphasize that 'The statements concerning values to be preserved should originate from the communities of users (bottom-up) and not only from the experts (top-down)' [3, p. 68].

\section{Stuck in the Middle? Urban Planning Between Communities and the Authorised Heritage Discourse}

It has been noted that cultural heritage policy has become increasingly focused on how, both, tangible and intangible heritage could be a vital resource for local communities, regions and industrial development, instead of focusing primarily on material assets and their preservation [31, p. 148]. Graham Fairclough points out that when landscape perspective is linked with the social aspects of heritage, mainstream policies, such as forms of spatial planning, are even more suitable for new heritage approaches than policies focused solely on heritage [10, p. 302]. Yet, the role of public administration and local policy-making has not been widely acknowledged in heritage management research, neglecting how these (f)actors shape heritage 
practices, conservation outcomes and the social impact of heritage [5, p. 147]. Perhaps because studying the impact of policy is comparable to trying to measure a moving target $[15, \mathrm{p} .7]$.

Although architecture and planning have been used in order to influence the society throughout history, as a 'pragmatic dimension of spatial modelling,' as Tiit Remm puts it, the sociocultural impacts of urban planning have been given a more widespread attention only since the spatial turn in humanities [26, p. 61]. The urban environment has been recognized to provide its inhabitants a structure of their sociocultural reality, as it 'incorporates physical space, social relations, sign systems and knowledge,' that give structure to 'the world people think they're living in every day' [25, p. 195]. Urban planning is no longer considered to be concentrated only on the physical forms, but rather as 'an instrument that regulates the life of the city' $[6$, p. 3]. The sociocultural aspects have come to hold a more central place in planning, as it has become widely acknowledged that "no development that wants to realize human potentials to their full measure can dispense with culture' [4, p. 31 ].27

As a form of cultural criticism [see in: 27], urban planning affects the ways we think about the city and also the urban heritage within it. During the process of the formation of visual and verbal planning documents, the urban space is reconstructed, its values and meanings revised, its heritage challenged. In this process, the structures, ideals, and values of the community are being spatialized [26, pp. 112-113]. The spatialization can also be considered as what Henri Lefebvre calls the production of space. How he describes it, is particularly telling considering the fate of urban heritage:

The production of space, having attained the conceptual and linguistic level, acts retroactively upon the past, disclosing aspects and moments of it hitherto uncomprehended. The past appears in a different light, and hence the process whereby that past becomes the present also takes on another aspect. [18, p. 65]

The way the past is recreated in the processes of production of space, including the processes of urban planning, recreates heritage by determining what is considered as heritage, by whom and for whom, what are its valuable features and how should they be maintained. Cultural heritage is no longer viewed, as it once was, as an object or a site, but rather as a process and an outcome [2, p. 24] and just like heritage is repeatedly going under revision, so should the ways of its management [10, p. 299].

Urban planning can help close the gap between the habitants and their environment, or it can push them even further away from each other. Experts have been making heritage decisions on behalf of societies for centuries, but the benefits of greater public participation have become more widely recognized [8, p. 91]. UNESCO's Recommendation on the Historic Urban Landscape emphasizes that in the process of urban planning a diverse cross-section of stakeholders should be involved and empowered to identify key values in their urban areas, and the mediation and negotiation of their inevitably conflicting interests should be facilitated throughout the process $[34, \mathrm{p} .4]$. Collaborative planning is a form of planning that aims to include more locals into shaping these definitions of environment, instead of leaving it all up to the administrative body to prescribe. It has been acknowledged to create 
greater democratic involvement also for the heritage process, as it helps to study what and for which reasons the society regards valuable [10, p. 297].

One of the ways to promote communities' involvement in heritage processes is value-based planning [8, p. 91]. 'Values-based approaches to heritage management have [...] been adopted' since The Australian Burra Charter in 1988 'put the idea of 'significance' at the heart of decision making, with the implication that significance was not something known by experts but something that needed to be discovered, and that understanding competing and conflicting values is the basis of heritage management' [8, p. 91].

There are several different approaches to distinguishing the values of cultural heritage and various heritage value typologies have been defined by different researchers and heritage organizations. In order to decrease confusion when discussing these values, it is useful to stick with just one approach in the following analysis. Randall Mason's take on heritage values divides them in two main categories: sociocultural values and economic values [20, p. 10]. In his approach the sociocultural values are historical, cultural (including symbolic and political values), social, spiritual/ religious, and aesthetic value; and the economical values are use value (or market value) and nonuse value in which he distincts existence, option and bequest value. In the following sections I will map out the values of milieu protection areas of Tartu, first, as they are represented in the comprehensive plan of Tartu, and second, as they are expressed in the local societies' feedback to the plan.

\section{Heritage Values of the Milieu Protection Areas in the Comprehensive Plan on Tartu}

In the comprehensive plan of Tartu [29], each milieu protection area is described in terms of plot structure, architectural style, and characteristic landscape elements, and its history is given from the first developments of which there still are some remains today until the 1930s-40s. The conditions for construction and renovation in these areas are given jointly with an exception of one area, i.e. Supilinn, which had its own set of rules established with a thematic plan a few years earlier. Since the conditions in the thematic plan were drawn out as a result of thorough debates and pithy collaboration between the town's administration and local inhabitants, it was decided they would be incorporated into the new plan without re-opening the discussion.

The comprehensive plan states the reason behind establishing milieu protection areas as follows: 'The aim of forming milieu protection areas is to secure the preservation of buildings, traditional plan structures, original plot patterns, street networks, streets, greenery, elements of landscape, and views that hold value of construction history' [29, p. 124]. Let's first look at the sociocultural values expressed in this statement. The historic value is explicitly in the foreground, although narrowed down to the history of construction. The statement sets focus on the historically formed urban landscape, and denotes that the urban heritage value lies in the link between physical substance and the intentions and actions of urban planners, architects, builders, and inhabitants of the bygone times. 
What exactly is considered to hold the value of construction history can be deduced from the conditions that are set in the plan for construction and renovation in these areas: this value is indisputably attributed to the urban environment and its substance that was formed before 1944. Any alteration or shift of course in the area's development or construction activities taken place since then is not considered to hold historical value. The possibility of attribution to heritage from the Soviet occupation period is discarded, as the changes that took place in this period are implied as disruptions or mistakes that need to be redone following the original design.

The political or ethnic values, both relevant for building cultural affiliation (the key aspect of cultural/symbolic values, as explained by Mason [21, p. 104]), are implied by the firm rule that divides the urban landscape elements into categories of valuable and invaluable by a point in time. Everything devised and realized before the year 1944 is considered to hold historical significance and value, and everything after that not. The craft or work-related value, indicating the process of making or building, is expressed more explicitly in the above cited statement. The intangible heritage of the milieu protection areas' traditions of craft and organizing the landscape is clearly highlighted.

In Mason's approach, the social value is closely related to the notion of social capital. The act of establishing the milieu protection areas itself can create and relocate social value. Since being a property owner or an inhabitant in the milieu area is increasingly perceived as a positive status, determining certain plots and buildings to hold the milieu value can also increase their social capital. As the quoted statement from the plan points out the valuable assets of the area, this can be regarded as a basis for the creation of social capital for every plot or building in the area. Meaning, the more value of history of construction the property holds, the more social capital it can potentially bring about.

Another relevant aspect of the social value is the aspect of 'place attachment' which according to Mason refers to 'the social cohesion, community identity and other feelings of affiliation that social groups derive from their 'home' territory's significance' [21, p. 105]. The plan clearly states which are the characteristic and valuable features of a given district, presenting these physical aspects as a basis for the identity of the district. To what extent they are actually perceived as such by the local communities is another matter. Nevertheless, this is an important aspect because the requirements for preservation and renovation of the historical substance are based on the view that they hold high identity value.

The spiritual/religious values that 'emanate from the beliefs and teachings of organized religion, but can also encompass secular experiences of wonder, awe and so on' [21, p. 105], are implied in the statement by referring to the values of the views which may be assumed to have the potential to induce the above mentioned secular experiences. This implication is based on an assumption that the sights of historical urban landscapes are something that people enjoy and value but only when they are preserved and restored according to their original appearances.

Last of the sociocultural values in Mason's typology is the aesthetic value which he defines as deriving from sensory experience. Not only from the visual qualities of heritage, but also from smells, sounds, and feelings, serving as an important factor for people's sense of well-being [21, p. 105]. As this is the most subjective of 
the values, it is often the cause for misunderstanding and conflict between heritage administrations and the public. While the authorised heritage discourse finds beauty in the authentic substance, excellently restored details, or high quality copies of the historic substance, there are many voices from the crowd that despise a worn out look, dislike the original style, or just praise the new and functional. The aesthetic preferences of the property owners often lead to deplorable actions, e.g. replacing the old wooden window frames with plastic ones, or installing modern facade covers and discarding the original wooden weatherboards with the rest of the facade decor. The radical contradictions in estimating aesthetic value are perceived as a great threat when considering the community input in defining the values of urban environment.

Use value, defined by Mason as a value that can be easily assigned a price [21, $\mathrm{p}$. 106], is not expressed in the quoted statement, neither, I would say, is it implied by any of the conditions set for construction and renovation in the areas. To construct new houses or renovate old ones in the milieu protection areas is generally more expensive than elsewhere, due to the set conditions. But since the overall improvement of the districts, combined with social changes in society, such as lifestyle preferences or rising appreciation for an historical urban environment, has remarkably raised the real estate value in these areas, earning a good profit from the investment is a good possibility. So we can conclude that indirectly the plan makes way for the use value to arise, though it is not considered as an end in itself.

All three categories of nonuse values are present in the plan. The bequest value is expressed explicitly in the quoted statement, as the clause 'to secure the preservation' is determining the imperative to save the mentioned landscape elements for the future, that is 'to bequeath a heritage asset to future generations' [21, p. 107]. The existence value can be seen in the requirements that call for preserving also the valuable details of landscapes and buildings that are visible only to the inhabitants themselves or in some cases only from a bird's eye view. This is to regard something valuable in itself, irrespective of whether it is witnessed and experienced by anyone. The option value can be seen in the general requirement to preserve the urban heritage in milieu protection areas even if today's inhabitants do not find it valuable nor claim it as their heritage. The underlying belief here is that the future inhabitants might do so and therefore we should preserve these assets.

So, to conclude, why is the historic urban landscape of the milieu protection areas in Tartu valuable according to the authorised heritage discourse expressed in the comprehensive plan? At first glance, looking at the stated aim of the protection areas and the list of conditions for construction and renovation, which are both focused on physical aspects of the area, the heritage values seem to lie solely in the tangible. But considering that (1) the focus in the plan is on the history of construction, (2) it proceeds from an imperative to preserve the historical substance or produce copies of it, and (3) the definition of 'historical' is clearly tied to a political interruption to the nation state, we can therefore conclude that the heritage here is foremost considered to be the intangible heritage of the tradition of construction and the organization of urban landscape prior to the Soviet occupation. Of course, as Laurajane Smith bluntly puts it, 'all heritage is intangible' [28, p. 3], yet this comes as a fruitful revelation as considering the milieu protection area heritage as essentially 
intangible heritage brings more clarity to the reasons why local heritage can remain distant to the communities.

\section{The Neighborhood Societies' Feedback to the Comprehensive Plan}

The comprehensive plan sets conditions for construction and renovation which are rather expensive to follow, demanding restoration of historical architectural details and handmade copies following the original design. For example, the cost of a full restoration of a large old double framed window can be as much as an average monthly income. This evokes a conflict of values for the inhabitants: on one end are the historical and cultural values (the appreciation for the old and architecturally valuable), and on the other is market value (the wish to minimize costs of building or renovating). Aesthetic value is also very actively involved, likely even the most dominant in our relationship to our living environment, but it could side with either end of this confrontation, as what is found to hold aesthetic value depends greatly on one's viewpoint on the visible and other sensory features of one's living environment. For example, while some people very much appreciate the traditional wooden windows with their particular design and details, and acknowledge the natural ventilation resulting from their incomplete airtightness, others would swear by the plain plastic ones to be nicer to look at and enjoy the comfort of better isolation from external factors like cold and windy weather.

To elicit the value categories present in the community identities, we'll be studying the feedback to the comprehensive plan of Tartu submitted by neighborhood societies of the milieu protection areas [30]. These societies are based on the idea that the inhabitants of the district form a distinguished local community and the formation of local identity is more or less explicitly considered to be one of the goals of the society. Neighborhood societies have been formed in four out of the ten milieu protection areas: Tähtvere (est. 2016), Tammelinn (est. 2015), Karlova (est. 2007), and Supilinn (est. 2002). In the creation of these community identities we can see that the municipality's discourse on milieu protection areas has had a great impact on them. All of these four societies name preservation of 'milieu value' as one of the goals for their activity, while not defining what milieu value means for them. Considering that in their feedback to the comprehensive plan they do not argue against any rules set for renovation and construction in the plan, even though they are often rather expensive to go by we can assume their acceptance of the signification of the term 'milieu value' as the municipality defines it in its statements and regulations. Although the areas have many inhabitants that individually protest against some of these rules or the concept of milieu protection areas in general, the neighborhood societies do not.

\subsection{Tähtvere}

The youngest of the neighborhood societies in the milieu protection areas of Tartu are the societies of Tähtvere and Tammelinn. The districts hold a lot in common 
regarding the urban landscape, having been planned and built in the 1920s and ' 30 s inspired by the garden city movement, but the societies' focus seems to be on different features of their living environment. Tähtvere Society's comments on the plan focus mostly on the urban landscape, building on the plan's description of the characteristics of the district's plot structure and building traditions. Regarding the plot structure, they are concerned with the number of buildings on the plot, their size and placement, which they argue should follow the nature of the district which they describe as 'inarguably a garden city type historic residential area with edifices erected prior to the Second World War as well as largely preserved greenery of the same period' [30].

The society argues for some points in the plan to be more attentive about preserving these characteristics also in its periphery, continuing to the other side of its borders, being driven by a concern that, while the plan sets conditions to preserve the urban historic landscape in the extent of the protected area, it does not prevent the adjacent plots outside the protected area from becoming more densely built up. They claim that without restrictive regulations the volume or placement of the new buildings there would be 'disturbingly in contrast' with the protected area, in a manner that would 'harm the living environment and the aesthetic milieu' of the protected area. In their concern on how the unwanted transformations in the adjoining area would increase the milieu value of the protected area we can detect aesthetic value once more, as they find it would be disturbing-it would not look or feel as nice as it does in the protected area-even though transformations taking place outside of the protected area would not cause changes to the historical substance within it. Also the market value could be implied here, as plots that offer more privacy and greenery are more valuable market-wise, and this value is likely to be decreased by new edifices being erected too close to the milieu area plots.

The society's comments and arguments are generally based on the view that the district's environment holds aesthetical and historical values, and that those are to be preserved. Their claims are mostly supported by an indication to the age of a tradition or substance, implying the historical value to be naturally assumed from that. Their comments also contain references to studies of the architecture of the area as well as the district's original garden city plan and its author, and the notion 'built heritage' is used to indicate the edifices, thereby explicitly acknowledging and declaring the historical value of the environment.

Important to note here is that their claims related to aesthetic values derive from their personal experiences and concerns, while the claims based on historical value are generally excerpted from documents formed by architectural historians and the municipality. The society's goals, I would argue, are mainly concerned with maintaining the aesthetic value of the area, advocating for it to continue to be an enjoyable living environment with relatively scarce housing, plenty of greenery, and quiet streets with as little noise and pollution as possible. The historical value is leaned on as an argument that can help accomplish these goals. The rise of market value is likely to be sensed as a positive outcome as well, because as the urban environments tend to become more dense, Tähtvere area's greenery and privacy becomes increasingly a luxury. 


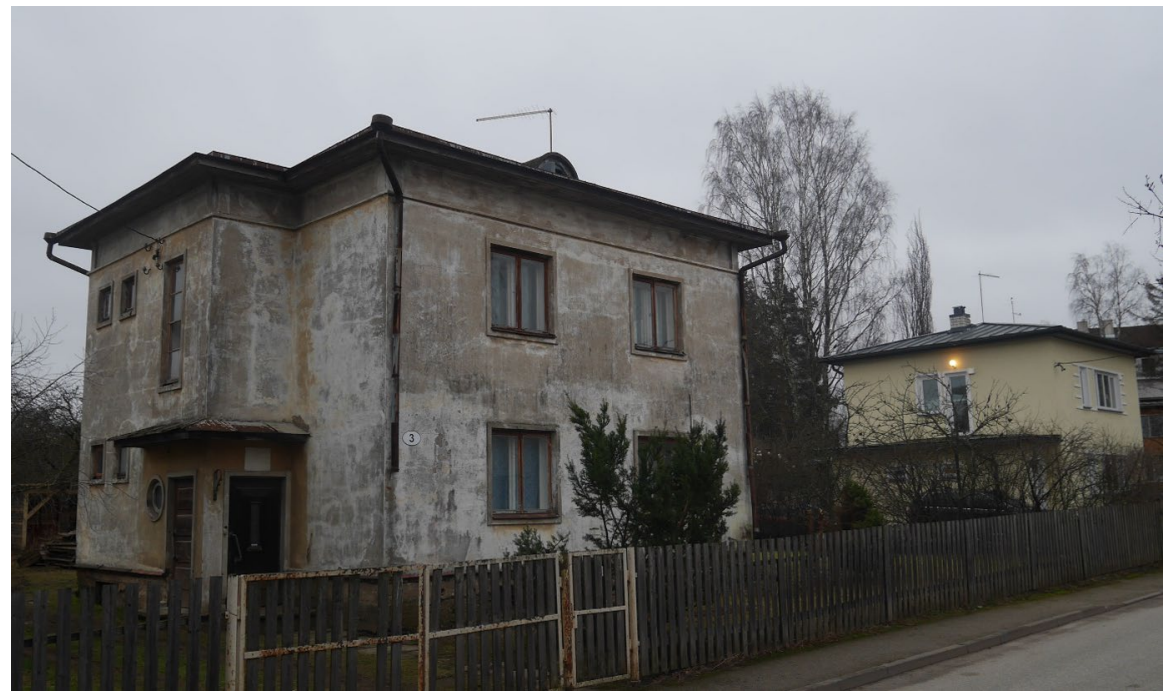

Tähtvere area consists of small apartment buildings with plastered facades characteristic to 1920 s and 30 s

\subsection{Tammelinn}

In Tammelinn Society's feedback to the comprehensive plan we'll find that, unlike in Tähtvere Society's comments, there is little reference given to historical edifices or plot structures. The focus of their feedback is mostly on mobility, an understandably pressing issue in a district located further away from the city centre, as opposed to Tähtvere district which is adjacent to the centre. Issues of parking, traffic, street network and bike lanes are approached repeatedly in their feedback, advocating for possibilities to be conveniently mobile either by car or by bike. Other comments highlight the role of playgrounds and sports fields. The points they make a plea for are aimed to increase the comforts and enjoyment of the environment, which in its essence is relatable to Mason's definition for the aesthetic value, i.e. sensory experiences in an environment that contribute to a sense of well-being [21, p. 105].

The ten-page commentary submitted by the society also mentions a few landscape related aspects that are considered to be important characteristics of the area. As the name of the district is Tammelinn, i.e. Oak Town, it is not surprising that the avenues rimmed with oak trees are considered essential for the "preservation of the Tammelinn milieu'. The society proposes to supplement more avenues of the kind and even to establish a nature protection area at the central Tamme avenue. These avenues rimmed with oak trees are without a doubt perceived as a dominating asset of the local landscape, central to the constructed sense of place, which is an important basis for their local identity.

In Tammelinn Society's commentary, a few remarks are also made referring to the possible size of future plots and edifices. The society argues for the size of future buildings not to exceed the existing ones and the size of future plots not to be 
allowed to be smaller than the historic ones. They claim that buildings with more than two stories would 'not fit in the garden city like residential area' and larger plots are 'necessary for maintaining a garden city like milieu and avoiding becoming too dense' [30]. Even though these references made to the district's landscape are infrequent in the commentary, they nevertheless are telling regarding the connections of community identity to the local landscape. The active value categories here are aesthetic and historical. Also, while less explicitly, the use value is implied, just like in some of the Tähtvere Society's arguments, that can be deducted to advocate for the market value not to be threatened by unwanted real estate developments in the area. Although the original plot structures are claimed to be preserved because of their historical value, we may also speculate that this cause is actually campaigned for in order to keep, both, the aesthetical and market values of one's own property that benefits from more greenery and less buildings in the neighbouring plots. So, just as in Tähtvere Society's commentary, we see how Tammelinn society takes on the historical values offered by the municipality only to argue for other values they prioritize.

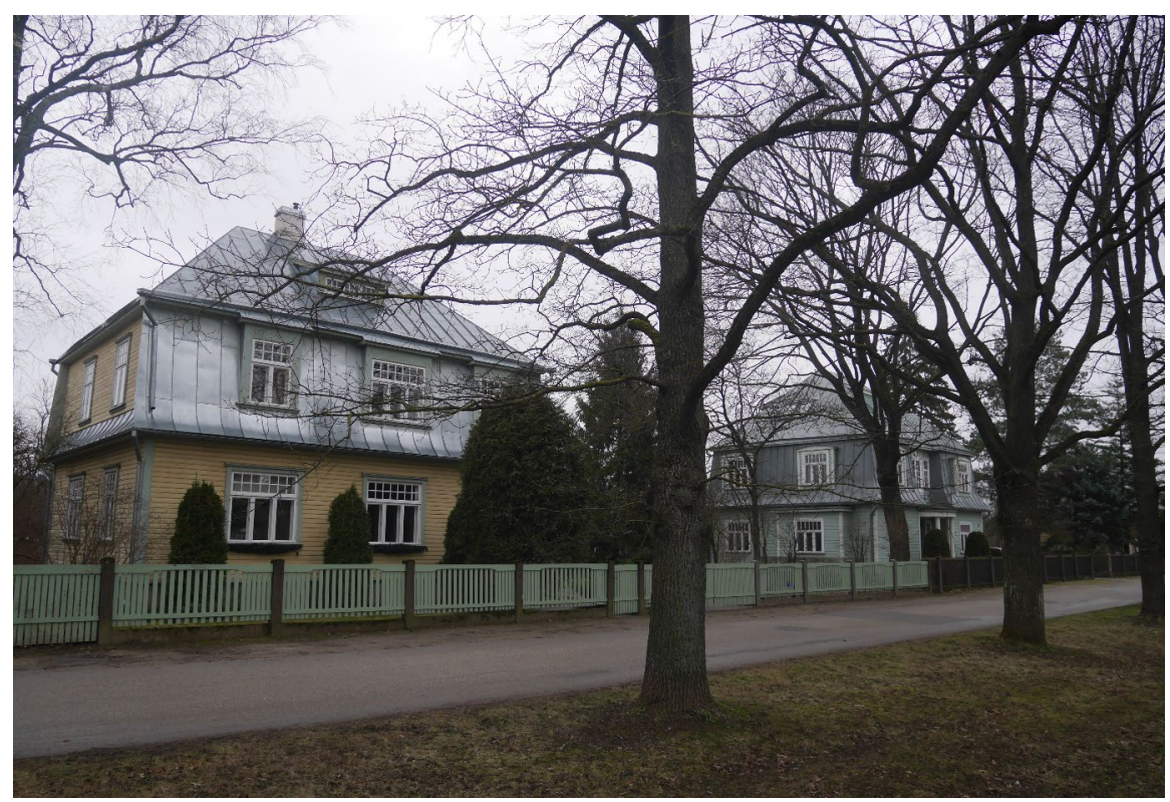

Villas characteristic of Tammelinn on Tamme avenue

\subsection{Karlova}

Karlova district's oldest remaining streets and houses date back to the late eighteenth century, while most of the area was built up over the 19th and in the beginning of the twentieth century. The district's Society has been working on the community identity formation for a much longer period of time than those of Tähtvere and 
Tammelinn, and has evolved to be more self-aware of its role as a meaning-making organization for the community. All of the sociocultural heritage values that Mason enlists are actively implied throughout their 15-page commentary, representing a versatile connection between the community and its living environment. Nonetheless, the social space (explicitly named so in their commentary) is only seldom represented intertwined with the urban heritage, e.g. in arguments promoting the preservation of traditional backyard landscapes, while generally the historical landscape and social life are treated separately.

The Karlova Society's promoted community identity is considered to be a rather good example that is expected to help preserve the historical urban landscape. Still, the problem of maltreatment of the historical substance is ongoing in the district. This indicates that the identity promoted by the Karlova Society has not been embraced by a big part of the inhabitants or not embraced entirely. I argue that since the aspects of social life values are in large stated separately from the heritage values, it is easy for the locals to accept only a part of this community identity which they find more relatable and comfortable to go by and yet not feel attached to other aspects of that same identity. I suggest that if the society's identity formation would connect the social life with heritage assets throughout their statements they could promote heritage values in the community identity more effectively.

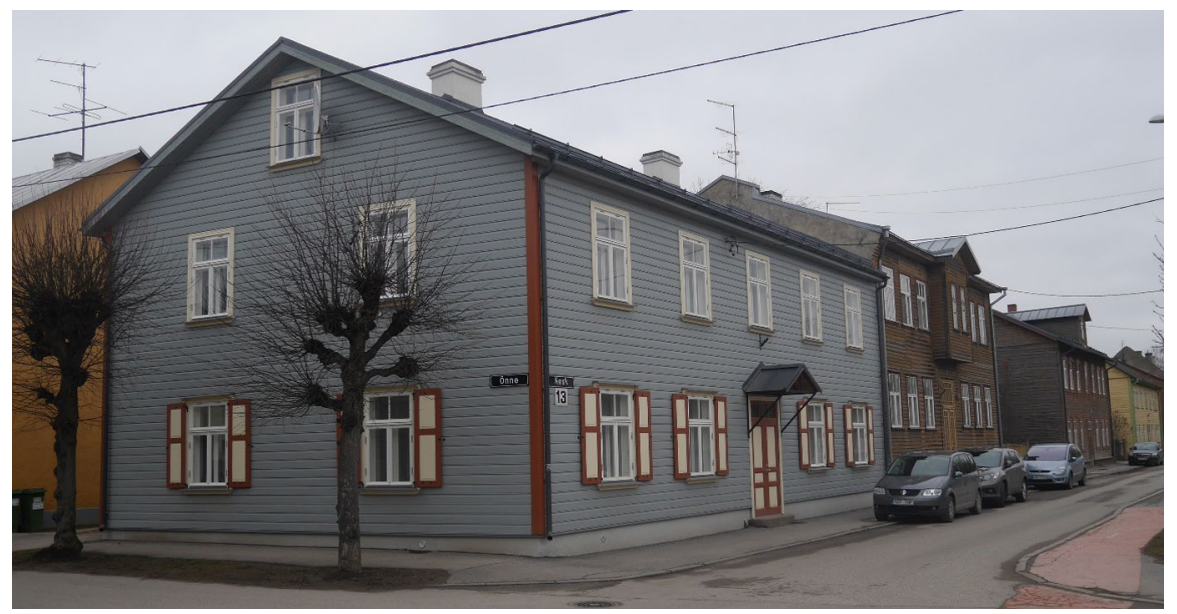

Typical housing of Karlova: two-story apartment buildings with wooden facade covers

\subsection{Supilinn}

The area named Supilinn has evolved from the eighteenth century, with most of today's housing dating to the nineteenth century. As mentioned earlier, Supilinn's thematic plan had been established briefly before the comprehensive plan was drawn out and it was fully incorporated into the new plan in order to avoid re-opening the discussion. Therefore the Supilinn Society did not provide feedback for the 
comprehensive plan. Yet, the differences in the area's description and the rules for construction and renovation, compared to the other milieu protection areas, are telling of the society's input during the collaborative planning process of the thematic plan. While the other areas are described by their histories up until the 1930s-40s, Supilinn's thematic plan included also a brief overview of the developments in the area from the 1940s up to the early 2000s, providing a more coherent storyline without any remarkable gaps. This narrative helps more clearly explain why buildings of some eras are considered more valuable and contributing to the area's identity than others.

The conditions for construction and renovation in Supilinn are more specific about some of the characteristic features of the area and also stricter in terms of preferring restoration to renovation. Regarding the use of traditional materials also in structure and insulation, while the conditions for other areas only determine the use of traditional materials in the exterior of the building. These more strict rules that prioritize historical value have been requested by the Supilinn Society, not suggested by the town's heritage department. There are several aspects contributing to a more urban heritage oriented community, but I believe a more cohesive narrative of the area's development to be one of them.

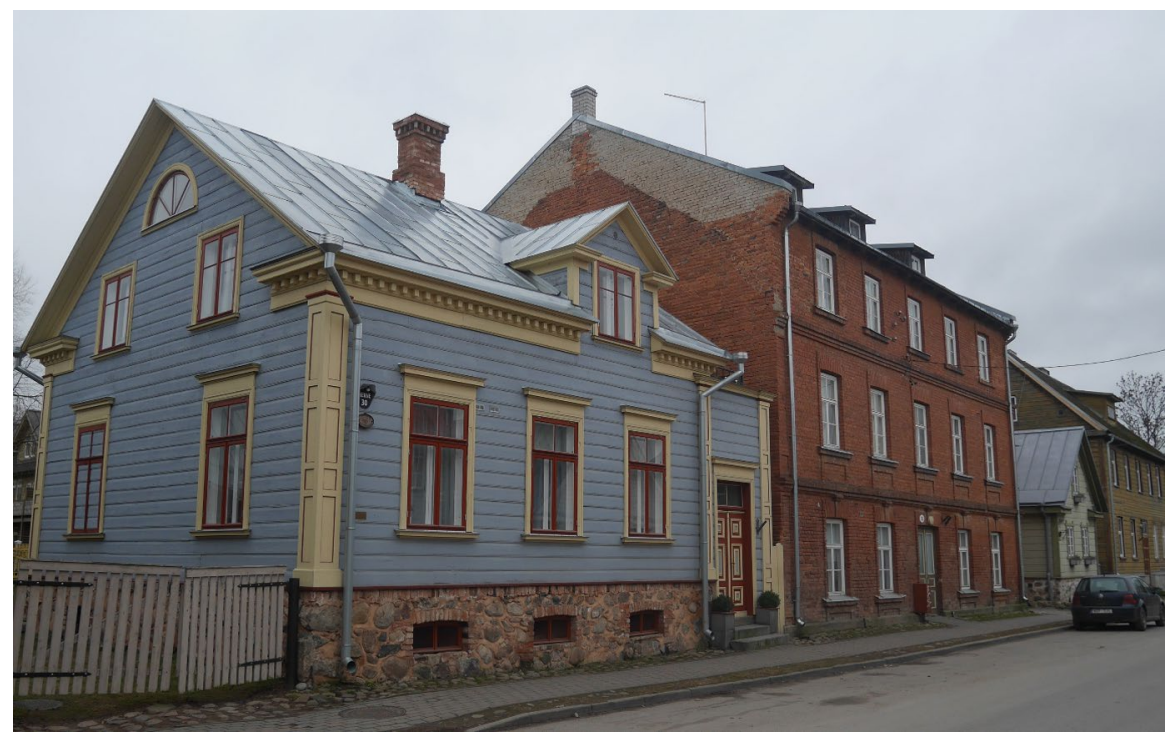

Typical urban landscape of Supilinn: smaller houses from the nineteenth century alternately with apartment buildings from the twentieth century. 


\section{Mediating Urban Heritage Values: A Narrative Approach}

Looking at the feedback and input of these four societies in the planning process, where no one rebels against or even questions the claimed values or set conditions, it seems that all is well with the preservation and maintenance of the historical urban landscape in these milieu protection areas. Unfortunately, that is not the case. When discussing the renovation process with homeowners, it often occurs that the historical and cultural values are pushed aside and the market value-and also the aesthetic value when it's believed to be in the modern materials-dominates the attitude and decisions. The usability, comfort and cost are prioritized over other features in the historical urban landscape when it comes down to one's own actions in the environment.

I find that the old town centers and monumental buildings are generally regarded to hold historical and cultural values in the public's eye-in addition to being usable spaces they are also perceived as works of art or mementos of our history, as something to be preserved and invested in. In the milieu protection areas, which mainly include residential buildings, the strongly dominant aspect in their perception is their liveability, the habit of living in them, to use Peirce's term- 'what a thing means is simply what habits it involves' [22, p. 12]. But that does not mean that their other values are bound to go unrecognized, since we are not just physical beings but also cultural ones - in order to get along in a society, we have to accommodate our behaviour also to 'soft facts' which are based on mutual beliefs about correct behaviour, and these intertwine with the hard facts, together forming the physical, social and cultural environment of our everyday lives, the space in which we live $[22$, p. 17]. We can affect which soft facts are related to urban heritage. To do so, I would argue, we need narratives to bind with the material objects-so that stories of the life of the building, the history of the neighbourhood, the local traditions of construction and way of life would become more easily related to the objects. The stories would become part of the habit of the object, and in so it's meaning.

Nigel Walter points out in his article 'From values to narrative' [36] that a narrative approach to historic buildings acknowledges that in most cases that 'story' has not reached its conclusion, and that to declare it closed is to bring its life to a premature end. Within a values-based methodology, what should be 'living' buildings are being 'killed off', so to speak, because it focuses on identifying abstract universals unbound by time and place. Walter claims:

To see a building as narrative is to acknowledge that the built environment is more than just a backdrop [...] against which we act out our lives, but is itself an active partner in our self-composition. Seeing a building as an ongoing and developing narrative is to acknowledge the relevance of the community's story to date-the building's biography_but also invites us to wonder where the 'story' might go next. [...] Crucially we should not imagine that our 'chapter' will be the last, but instead we have a duty to our 'co-authors' to leave space for those who follow after us to write theirs. [36, p. 645] 
In the comprehensive plan of Tartu, I find the role of, both, men and buildings in the narrative to be somewhat unclear and the storyline incomplete. We are given information about the developments of the areas between two points in time: from the construction of the older buildings still there today until the 1940s when Estonia became occupied by the Soviet Union. It is this period in time that today's resident and community must connect to- - but how are they to position themselves regarding that storyline? The narrative in the comprehensive plan suggests that during the period described, a valuable urban space was created. It is indicated that this valuable space was altered and to some extent destructed due to the occupation, losing some of its value, and that today we should carry on from where the story got cut off, where its intended fate was interrupted. But not giving us the whole story creates a situation where people don't quite see how they are to enter this storyline- - or that they have entered it at all-and which role is theirs to take on.

Sharing narratives forwarding the historical values could result in this value becoming a more widespread interpretation of the living environment, perceived as a crucial factor for (1) cultural value, as local heritage becomes something that is essential for, both, collective and personal identity, (2) aesthetic value, as appreciation of historical substance tends to make it perceived as more beautiful and enjoyable, and (3) use value, as the general increase of appreciation towards historical substance makes it also become more valuable market-wise.

\section{Conclusion}

What we find studying the societies' feedback is not always explicitly related to the urban heritage of a district, but it indicates which value categories are most relevant in the people's relation with their living environment. Detecting the priorities of the urban environment for its inhabitants can help us better plan presenting, explaining, reviving and preserving the urban heritage. Fines don't make a fine example-the possible threat of a penalty from the administration seems to be less effective in preventing the maltreatment of the tangible heritage than social condemnation. If a community holds a strong position regarding the treatment of the built environment then the prospective negative judgement that would fall down on the property owner who goes against the community's practice would prove to be a more efficient means of heritage preservation than any official policy. Where the policy and community ideals overlap, there the outlook for preservation is most promising.

The formation of identities requires narratives. It is suggested to be 'the only way in which human beings can conceptualise self-identity' [32, p. 211]. Currently the authorised heritage discourse is offering narratives that are concentrated on physical aspects of the environment. As history of architecture and planning will likely remain a priority for a minority in the society, more attention should be given to social narratives uniting historic and present-day identities, and historic values with other value categories more active in people's relation to the environment, i.e. aesthetic, use, and cultural values. Stories make things and spaces meaningful, and even when their details are forgotten, the significance they have given to the place and material is likely to stick. We might forget the reason behind why a building or a 
landscape is culturally significant, but we will still remember that it is of value if the story has once made an impact on our perception of the environment.

Just as cultural heritage is always in transformation, so are also the philosophies and policies regarding its preservation. To promote identity formation through heritage policies should be treated as a possibility to decrease the distance between local urban heritage and the community, which is likely best accomplished if the policies are developed together with the community. Collaborative planning can be regarded as an effective tool for mapping the inhabitants' attitudes and values regarding their environment. Sure, there are some threats in this collaboration if all of the communities' opinions are to be regarded as 'good' and 'right', since 'this ignores the fact that sometimes local communities are among the main threats to heritage preservation, due to their speculative, political or even criminal interests' [19, p. 113]. Also, a weaker community leaves the upper hand in heritage debates to the municipality, while a community that has its own ideas and views on its heritage can be a difficult partner to work with since they want to decide for themselves which regulations are right for their landscape and community, as seen in the Supilinn case in Tartu. But if the goal is for the urban heritage to also live on in the communities that inhabit these landscapes, not only in the material, it is worth figuring out the best possible strategies for each area.

The promotion of identity formation should be largely focused on providing cohesive narratives about the history of the urban landscape and finding ways to link this to the social and cultural life of the today's inhabitants, creating stronger ties between the material and mental dimensions of the urban landscapes. While it is important to emphasize the historical values, the functionality of a living environment should not be underestimated among the heritage discourse. Instead, more thought should be given to how to achieve better symbiosis between the historical environment and the expectations for the comforts of contemporary lifestyle-so that the historical urban landscapes would not become solely historical but also remain very much urban, i.e. filled with people who continue the stories of these culturally significant places.

Acknowledgements This work has been carried out with the support of the European Regional Development Fund which has enabled me to spend inspiring days in the ICCROM Library in Rome (Dora Plus T 1.2 grant) and take part in a doctoral writing retreat in Estonia (Tallinn University's ASTRA project, activity D40, University of Tartu ASTRA project PER ASPERA, Estonian Academy of Arts ASTRA project, EKA LOOVKÄRG and Estonian Academy of Music and Theatre ASTRA project, EMTASTRA).

Open Access This article is licensed under a Creative Commons Attribution 4.0 International License, which permits use, sharing, adaptation, distribution and reproduction in any medium or format, as long as you give appropriate credit to the original author(s) and the source, provide a link to the Creative Commons licence, and indicate if changes were made. The images or other third party material in this article are included in the article's Creative Commons licence, unless indicated otherwise in a credit line to the material. If material is not included in the article's Creative Commons licence and your intended use is not permitted by statutory regulation or exceeds the permitted use, you will need to obtain permission directly from the copyright holder. To view a copy of this licence, visit http://creativecommons.org/licen ses/by/4.0/. 


\section{References}

1. Alatalu, R. 2012. Muinsuskaitse siirdeühiskonnas 1986-2002: Rahvuslikust südametunnistusest Eesti NSV-s omaniku ahistajaks Eesti Vabariigis. Tallinn: Eesti Kunstiakadeemia.

2. Ashworth, G.J. 2008. Paradigms and paradoxes in planning the past. In Selling or telling? Paradoxes in tourism, culture and heritage, ed. M.K. Smith and L. Onderwater. Atlas reflections, Arnhem: Association for Tourism and Leisure Education.

3. Bandarin, F., and R. van Oers. 2012. The historic urban landscape: Managing heritage in an urban century. Chichester: Wiley-Blackwell.

4. Bianca, S. 2010. Historic cities in the 21st century: Core values for a globalizing world. In Managing historic cities $=$ Gérer les villes historiques, ed. R. van Oers and H. Sachiko Haraguchi. Paris: UNESCO World Heritage Centre.

5. Bonini Baraldi, S., and L. Zan. 2017. The heritage chain: Assessing the economic organization of the sector. In Managing cultural heritage an international research perspective, ed. L. Zan, S. Boninibaraldi, M. Lusiani, D. Shoup, P. Ferri, and F. Onofri. London: Routledge.

6. Cagnardi, A. 1995. Un senso nuovo del piano. Milano: Etaslibri.

7. Choay, F. 2001. The invention of the historic monument. Cambridge: Cambridge University Press.

8. Clark, K. 2008. Only connect-sustainable development and cultural heritage. In The heritage reader, ed. G. Fairclough, R. Harrison, J.H. Jameson Jnr, and J. Schofield. London: Routledge.

9. Crişan, R. 2013. Regeneration in (teaching) conservation. In CONSERVATION/ REGENERATION: The modernist neighbourhood, ed. S.F. Giovanna, R. Crisan, K. Loughlin, G. Franco, et al. European Association for Architectural Education (EAAE): University Press.

10. Fairclough, G. 2008. New heritage, an introductory essay-people, landscape and change. In The heritage reader, ed. G. Fairclough, R. Harrison, J.H. Jameson Jnr, and J. Schofield. London: Routledge.

11. Fairclough, N. 2001. The discourse of new labour: Critical discourse analysis. In Discourse as data: A guide for analysis, ed. M. Wetherell. London: Sage and the Open University.

12. Giovannoni, G. 1999 [1931]. Vecchie città ed edilizia nuova. Milano: Città Studi Edizioni srl.

13. Hansar, L. 2006. Criteria of identity-Activities in Estonia. In Sustainable historic towns-urban heritage as an asset of development. Project report, ed. M. Lehtimäki.

14. Hall, S. [1999] 2008. Whose heritage? In The heritage reader, eds G. Fairclough, Graham, R. Harrison, J.H. Jameson Jnr, J. Schofield. London: Routledge.

15. Hobson, E. 2004. Concervation and planning: Changing values in policy and practice. London: Spon Press.

16. ICOMOS Brazil. 1987. First Brazilian seminar about the preservation and revitalization of historic centers. https://www.icomos.org/en/resources/charters-and-texts/179-articles-en-francais/ressources /charters-and-standards/194-first-brazilian-seminar-about-the-preservation-and-revitalization-ofhistoric-centers-itaipava.

17. Kull, K., K. Lindström, M. Lotman, R. Magnus, K. Maimets, T. Maran, RTh Moss, Ü. Pärli, K. Pärn, A. Randviir, T. Remm, S. Salupere, V. Sarapik, E. Sütiste, P. Torop, A. Ventsel, V. Verenitš, and K. Väli. 2018. Semiootika. Tartu: Tartu Ülikooli Kirjastus.

18. Lefebvre, H. 1991. The prduction of space. Oxford: Basil Blackwell.

19. Lusiani, M., and L. Zan. 2013. Planning and heritage. Journal of Cultural Heritage Management and Sustainable Development 3 (2): 108-115.

20. Mason, R. 2002. Assessing values in conservation planning: Methodological issues and choices. In Assessing the values of cultural heritage, ed. M. De la Torre. The Getty Conservation Institute: Los Angeles.

21. Mason, R. 2008. Assessing values in conservation planning: Methodological issues and choices. In The heritage reader, ed. G. Fairclough, R. Graham, et al. London: Routledge.

22. Määttänen, P. 2006. Space, time and interpretation. In KOHT ja PAIK/PLACE and LOCATION. Studies in environmental aesthetics and semiotics V, ed. E. Näripea, V. Sarapik, and J. Tomberg. Tallinn: Estonian Academy of Arts.

23. Murzyn-Kupisz, M., and J. Działek. 2013. Cultural heritage in building and enhancing social capital. Journal of Cultural Heritage Management and Sustainable Development 3 (1): 35-54.

24. Nurme, S., Z. Kotval, N. Nutt, M. Hiob, and S. Salmistu. 2014. Baroque manorial cores and the landscape. Journal of Cultural Heritage Management and Sustainable Development 4 (2): 166-183. 
25. Remm, T. 2012. Tajuline, objektiivne ja sümboliline linnaruum Supilinnas. Acta Architecturae Naturalis 2: 193-207.

26. Remm, T. 2015. Sociocultural space: Spatial modelling and the sociocultural world. Tartu: University of Tartu Press.

27. Remm, T. 2015. Planeerimine kui kriitika. Välieluruumi ajakiri Õu 9: 49-53.

28. Smith, L. 2006. Uses of heritage. London: Routledge.

29. Tartu Linnavalitsus [=Tartu City Council]. 2017. Tartu linna üldplaneering 2030+. https://www. tartu.ee/sites/default/files/uploads/Linnaplaneerimine/Tartu_yldplaneering_2017.pdf.

30. Tartu Linnavalitsus. 2017. Tartu linna üldplaneeringu ettepanekud ja linna seisukohad. https:// www.tartu.ee/sites/default/files/uploads/Linnaplaneerimine/Yp_ettepanekud_seisukohad2017.pdf.

31. Thorkildsen, A., and M. Ekman. 2013. The complexity of becoming: Collaborative planning and cultural heritage. Journal of Cultural Heritage Management and Sustainable Development 3 (2): 148-162.

32. Thomas, J. 1995. Reconciling symbolic significance with being-in-the-world. In Interpreting archaeology: Finding meaning in the past, ed. I. Hodder, M. Shanks, A. Alexandri, V. Buchli, J. Carmen, J. Last, and G. Lucas. London: Routledge.

33. Tomps, F. 1987. Complex preservation and present-day use of historical architectural ensembles in Estonia. In ICOMOS 8th general assembly, symposium papers, Vol. 1. 212-218.

34. UNESCO. 2011. UNESCO recommendation on the historic urban landscape (HUL). http://www. unesco.org/new/en/unesco/resources/online-materials/publications/unesdoc-database/historicur banlandscape.

35. Välja, L. 2008. Urban wooden architecture-traditions and significance. In KOHT ja PAIK/PLACE and LOCATION. Studies in environmental aesthetics and semiotics VI, ed. E. Näripea, V. Sarapik, and J. Tomberg. Tallinn: Estonian Academy of Arts.

36. Walter, N. 2014. From values to narrative: A new foundation for the conservation of historic buildings. The International Journal of Urban Policy and Planning 20 (6): 634-650.

37. Waterton, E., L. Smith, and G. Campbell. 2006. The utility of discourse analysis to heritage studies: The Burra charter and social inclusion. International Journal of Heritage Studies 12 (4): 339-355.

Publisher's Note Springer Nature remains neutral with regard to jurisdictional claims in published maps and institutional affiliations. 